\title{
Deep hypothermic circulatory arrest during the arterial switch operation is associated with reduction in cerebral oxygen extraction but no increase in white matter injury
}

\author{
Paul P. Drury, BSc(Hons), ${ }^{\mathrm{a}}$ Alistair J. Gunn, MBChB, PhD, ${ }^{\mathrm{a}}$ Laura Bennet, $\mathrm{PhD},{ }^{\mathrm{a}}$ \\ Anusha Ganeshalingham, MBChB, ${ }^{\mathrm{b}}$ Kirsten Finucane, $\mathrm{MBChB},{ }^{\mathrm{c}}$ David Buckley, $\mathrm{MBChB},{ }^{\mathrm{b}}$ and \\ John Beca, MBChB ${ }^{\mathrm{b}}$
}

\begin{abstract}
Objective: Deep hypothermic circulatory arrest may be associated with increased neural injury. We investigated whether short periods of deep hypothermic circulatory arrest are associated with altered neurophysiologic recovery or greater risk of injury.
\end{abstract}

\begin{abstract}
Methods: Eighteen term infants with transposition of the great arteries undergoing the arterial switch operation were enrolled. Deep hypothermic circulatory arrest was used in 11, and bypass alone in 7 . Near-infrared spectroscopy and amplitude-integrated electroencephalography were recorded with standard monitoring during and from 4 to $16 \mathrm{~h}$ after surgery. Fractional tissue oxygen extraction was determined from arterial oxygen saturation and venous weighted intracerebral oxygenation. Magnetic resonance imaging was performed before and 5 to 7 days after surgery.
\end{abstract}

\begin{abstract}
Results: There were no significant differences between patients requiring deep hypothermic circulatory arrest (median, $5 \mathrm{~min}$; range, 3-6 min) or cardiopulmonary bypass only at the beginning of surgery. At the end of surgery, amplitude-integrated electroencephalography minimum amplitude was significantly lower in the deep hypothermic circulatory arrest group $(P<.05)$, and fractional tissue oxygen extraction tended to be lower $(P=.068)$. After surgery, deep hypothermic circulatory arrest was associated with significantly higher tissue oxygenation index, lower fractional tissue oxygen extraction, and lower core temperature $(P<.05)$. Magnetic resonance imaging-defined white matter injuries before and after surgery were similar between groups.
\end{abstract}

Conclusions: In this prospective, observational study, brief deep hypothermic circulatory arrest during arterial switch was associated with reduced cerebral oxygen uptake during recovery, with transient electroencephalographic suppression but no increase in risk of white matter injury. (J Thorac Cardiovasc Surg 2013;146:1327-33)

The role of deep hypothermic circulatory arrest (DHCA) in the repair of congenital heart disease (CHD) during infancy remains controversial, with significant variation among institutions and surgeons. ${ }^{1}$ Some use relatively long periods of DHCA to facilitate surgical repair of the defect, some use very brief periods of DHCA only (eg, for surgery on the atrial septum when there is no other intracardiac surgery or during transfer of cannulas while using antegrade

\footnotetext{
From the Fetal Physiology and Neuroscience Group, ${ }^{a}$ Department of Physiology, University of Auckland, Auckland, New Zealand; and the Pediatric Intensive Care Unit, ${ }^{\mathrm{b}}$ and Pediatric and Congenital Cardiac Services, ${ }^{\mathrm{c}}$ Starship Children's Hospital, Auckland, New Zealand.

Supported by the National Heart Foundation of New Zealand, Auckland Medical Research Fund, Green Lane Research and Education Fund, and the Health Research Council of New Zealand. P.P.D. is supported by the New Zealand Neurological Foundation W\&B Miller Doctoral Scholarship.

Disclosures: Authors have nothing to disclose with regard to commercial support.

Received for publication Sept 22, 2012; revisions received Jan 2, 2013; accepted for publication Feb 12, 2013; available ahead of print March 18, 2013.

Address for reprints: John Beca, MBChB, Pediatric Intensive Care Unit, Starship Children's Hospital, Park Rd, Grafton, Auckland 1023, New Zealand (E-mail: JohnBeca@adhb.govt.nz).

$0022-5223 / \$ 36.00$

Copyright (C) 2013 by The American Association for Thoracic Surgery

http://dx.doi.org/10.1016/j.jtcvs.2013.02.011
}

cerebral perfusion), and some avoid DHCA entirely. The advantages of DHCA are that it provides a bloodless, uncluttered surgical field; simplifies cannulation; and limits exposure of blood to foreign surfaces, with less resulting inflammation. The major potential disadvantage is that it might lead to ischemic brain injury and worse neurodevelopmental outcomes. There is little doubt that prolonged DHCA increases the risk of brain injury ${ }^{2-4}$; however, it is unknown whether shorter periods are also associated with increased risk. The Boston Circulatory Arrest Study found that DHCA was associated with worse motor and speech problems, whereas continuous cardiopulmonary bypass (CPB) was associated with problems in several behavioral domains. ${ }^{3,5}$ Subsequent randomized control trials of aspects of perfusion management during CPB and a prospective cohort study have not found an association between DHCA and adverse neurodevelopmental outcomes. $^{1}$

Magnetic resonance imaging (MRI) studies have shown that white matter injury (WMI) is the most common pattern of brain injury in infants with CHD. WMI is reported in $25 \%$ to $40 \%$ of infants before surgery, and new injury is reported in approximately $40 \%$ to $50 \%$ after surgery. ${ }^{6-10}$ 


$$
\begin{aligned}
& \text { Abbreviations and Acronyms } \\
& \Delta \mathrm{Hb}=\text { difference in hemoglobin } \\
& \text { aEEG = amplitude-integrated } \\
& \text { electroencephalography } \\
& \mathrm{aEEG}_{\min }=\text { electroencephalographic minimum } \\
& \text { amplitude } \\
& \text { ASO = arterial switch operation } \\
& \text { CHD = congenital heart disease } \\
& \mathrm{CPB}=\text { cardiopulmonary bypass } \\
& \text { DHCA }=\text { deep hypothermic circulatory arrest } \\
& \mathrm{Hb}=\text { deoxyhemoglobin } \\
& \mathrm{HbO}_{2}=\text { oxyhemoglobin } \\
& \text { EEG = electroencephalography } \\
& \text { FTOE = fractional tissue oxygen extraction } \\
& \text { MAP = mean arterial blood pressure } \\
& \text { MRI = magnetic resonance imaging } \\
& \text { NIRS = near-infrared spectroscopy } \\
& \mathrm{SaO}_{2}=\text { arterial oxygen saturation } \\
& \text { TGA }=\text { transposition of the great arteries } \\
& \text { TOI = tissue oxygenation index } \\
& \text { VSD }=\text { ventricular septal defect } \\
& \text { WMI = white matter injury }
\end{aligned}
$$

Lower regional cerebral oxygen saturation, as measured with near-infrared spectroscopy (NIRS), has been associated with new ischemic lesions on MRI after the Norwood procedure and with MRI abnormalities and a lower psychomotor development index at 1 year of age in infants undergoing a biventricular repair. ${ }^{11}$

The arterial switch operation (ASO) for correction of transposition of the great arteries (TGA) provides a useful cohort to study the effects of different operative and perfusion techniques. It is relatively common, carries a very low surgical mortality, is associated with a relatively standard anatomy and age of repair, and is rarely associated with genetic syndromes. A common surgical approach in infants with TGA and an intact ventricular septum is to use a single venous drainage cannula in the right atrium and continuous $\mathrm{CPB}$ with a short period of DHCA to close the atrial septum; the alternative is to use bicaval venous cannulation and thereby avoid the need for DHCA.

The goal of this study was to investigate whether very short periods of DHCA are associated with differences in cerebral oxygenation, electroencephalographic (EEG) amplitude and injury on MRI scan relative to infants undergoing surgery for TGA without DHCA.

\section{MATERIALS AND METHODS}

This study was part of a larger prospective longitudinal study of brain injury in infants undergoing surgery for CHD conducted at Starship Children's Hospital, Auckland, New Zealand. Infants were included in this substudy if they had TGA with or without a ventricular septal defect (VSD) and underwent an ASO. Infants were excluded if they were less than 36 weeks' gestational age at birth or if they had a recognized genetic or malformation syndrome. The study population consisted of infants who also underwent continuous NIRS and EEG monitoring during and after surgery and had MRI scans performed before and after surgery. Informed consent was obtained from parents or caregivers, and the study was approved by the local human research and ethics committee. Demographic and physiologic data were collected prospectively by the study research nurses.

\section{Clinical Management}

Balloon atrial septostomy was performed under ultrasonographic guidance in the intensive care unit if required according to clinical and echocardiographic assessment. For ASO, anesthesia was induced and maintained with fentanyl, isoflurane, and muscle relaxants. Cannulation for CPB was performed with a single venous cannula in the right atrium and an aortic cannula. In selected infants, either those with a VSD or because of surgical preference related to size or anatomic considerations, the venous cannula was then replaced by bicaval cannulas in the superior and inferior venae cavae. Infants who had a single venous cannula throughout had a short period of DHCA to allow closure of the atrial septum. The perfusion strategy included continuous full-flow $\mathrm{CPB}$ at $150 \mathrm{~mL} /(\mathrm{kg} \cdot \mathrm{min})$ and a target core temperature of $22^{\circ} \mathrm{C}$. Alpha-stat $\mathrm{pH}$ management was used when the core temperature was greater than $30^{\circ} \mathrm{C}$; below this threshold, $\mathrm{pH}$-stat was used during both cooling and rewarming.

Phenoxybenzamine was given to all infants before or during CPB. Vasodilatation was maintained after surgery with either phenoxybenzamine or a milrinone infusion. Dopamine or epinephrine infusions were used as required to maintain systemic cardiac output and blood pressure. After surgery, analgesia and sedation were managed with a continuous infusion of morphine and either a midazolam infusion or intermittent boluses of diazepam.

\section{Electroencephalography}

Continuous amplitude-integrated electroencephalography (aEEG) was performed with the Research Brain Rescue Monitor (ReBRM; BrainZ Instruments Ltd, Auckland, New Zealand). Left and right parietal and frontal cortices were monitored with standard international electrode positioning and signal processing as previously described elsewhere. ${ }^{12}$ The primary variable was the EEG minimum amplitude $\left(\mathrm{aEEG}_{\mathrm{min}}\right)$, which reflects background EEG activity. ${ }^{12}$ aEEG data were included for analysis if the electrode impedance was less than $10 \mathrm{k} \Omega$ per pair and free from electrical artifact. Electrographic seizures were identified on aEEG recordings and then confirmed on the continuous EEG trace on the basis of a duration longer than 10 seconds with amplitude greater than $40 \mu \mathrm{V}$ and a repetitive evolving pattern. ${ }^{12}$

\section{NIRS Measurements}

Concentration changes in global cerebral oxyhemoglobin $\left(\mathrm{Hbo}_{2}\right)$ and deoxyhemoglobin $(\mathrm{Hb}$ ), normalized total hemoglobin index (sum of $\left[\mathrm{HbO}_{2}\right]+[\mathrm{Hb}]$ ), and cerebral tissue oxygenation index (TOI) were measured with a NIRO-200 spectrophotometer (Hamamatsu Photonics KK, Hamamatsu City, Japan). TOI is the venous-weighted fraction of oxygenated hemoglobin: $\left[\mathrm{HbO}_{2}\right] /\left(\left[\mathrm{Hbo}_{2}\right]+[\mathrm{Hb}]\right)$. Fractional tissue oxygen extraction (FTOE) was calculated from the TOI and the arterial oxygen saturation $\left(\mathrm{SaO}_{2}\right)$ as $\left(\mathrm{SaO}_{2}-\mathrm{TOI}\right) / \mathrm{SaO}_{2}$. Difference in hemoglobin $(\Delta \mathrm{Hb})$ was calculated as $\left[\mathrm{Hbo}_{2}\right]-[\mathrm{Hb}]$, which correlates well with cerebral blood flow given stable hematocrit and arterial oxygen saturation. ${ }^{13}$

\section{Brain MRI Protocol}

MRI studies were performed with a 1.5-T Magnetom Avanto (Siemens, Erlangen, Germany) scanner. Standardized sequences were used for all studies, including coronal 3D-FLAIR $\mathrm{T}_{1}$-weighted images $(1 \mathrm{~mm}$ slice thickness), coronal and axial $\mathrm{T}_{2}$-weighted dual-echo, fast spin-echo images ( $2 \mathrm{~mm}$ slice thickness), and axial diffusion-weighted imaging (12-20 
directions, $4 \mathrm{~mm}$ slice thickness). Scans were reported by an experienced neuroradiologist who was blinded to the study. Brain injury was defined as the presence or absence of focal infarction (stroke), WMI, or hemorrhage (intraventricular or parenchymal), as previously defined elsewhere. ${ }^{6} \mathrm{WMI}$ severity was classified as normal (no WMI), mild ( $\leq 3$ foci and all $\leq 2 \mathrm{~mm}$ ), moderate ( $>3$ and $\leq 10$ foci, or any foci $>2 \mathrm{~mm}$ ), and severe ( $>10$ foci). There were no adverse events related to MRI studies.

\section{Data Collection and Analysis}

Heart rate, mean arterial blood pressure (MAP), left and right atrial pressures, peripheral $\mathrm{SaO}_{2}$, core temperature, and aEEG and NIRS variables were recorded continuously. Data were stored and then analyzed off-line with customized software (Chart Analyzer, Labview 2004; National Instruments Corporation, Austin, Tex). Five standardized time periods were defined a priori for intraoperative data analysis and presentation to account for differences in surgery duration between patients. Five-minute averages (1) beginning 30 minutes before and lasting until 30 minutes after initiation of $\mathrm{CPB}$, (2) from 10 minutes before and lasting until 10 minutes after aortic cross-clamping, (3) from 10 minutes before and lasting until 10 minutes after DHCA where used (with 1-minute averages during DHCA), (4) from 10 minutes before and lasting until 10 minutes after aortic unclamping, and (5) from 30 minutes before and lasting until 30 minutes after termination of $\mathrm{CPB}$. Data were not collected during transfer of the infant from the operating room to intensive care. Postoperative recordings commenced from arrival in the intensive care unit until the first postoperative morning; 4 to 16 hours after termination of $\mathrm{CPB}$ was used as the period of postoperative data that was the most consistent between patients.

\section{Statistical Analysis}

Demographic, preoperative, and surgical data were tested with analysis of variance or Mann-Whitney $U$ test if not normally distributed with the SPSS 15.0 statistical software (IBM Corporation, Armonk, NY). Categoric data were compared with the Fisher exact test. Within-group and betweengroup comparisons were made with repeated measures analysis of variance, and post hoc contrasts tests were used when significance was found with JMP 8.0 (SAS Institute Inc, Cary, NC). The period from 10 to $30 \mathrm{~min}$ utes before bypass started was used as prebypass baseline values. These were compared with an average of 10 to 30 minutes after bypass and analyzed with paired $t$ tests to assess within-group changes before and after bypass. The DHCA nadir was also tested against the baseline value with paired $t$ tests. Data are presented as either mean \pm SEM or median and range as appropriate.

\section{RESULTS}

Eighteen infants were included in this analysis. Of these infants, 11 had a short period of DHCA and 7 had CPB without DHCA. The median duration of DHCA was 5 minutes (range, 3-6 minutes). The characteristics of the study population are shown in Table 1. The DHCA group had slightly lower weight and gestational age at birth, and none had a VSD (0/11 vs 3/7 non-DHCA patients). There were no differences between groups before surgery in severity of hypoxemia (lowest $\mathrm{PaO}_{2}$ and $\mathrm{SaO}_{2}$ ) or cardiovascular dysfunction (lowest MAP, lowest $\mathrm{pH}$, and highest lactate). There were no significant differences between groups in CPB time, aortic crossclamp time, minimum temperature during $\mathrm{CPB}$, or time during surgery with TOI less than $50 \%$.

The time sequence of changes in physiologic variables during and after ASO are shown in Figures 1 and 2,
TABLE 1. Demographic and preoperative data

\begin{tabular}{|c|c|c|c|}
\hline Parameter & $\begin{array}{c}\text { DHCA } \\
(\mathbf{n}=11)\end{array}$ & $\begin{array}{c}\text { No DHCA } \\
(n=7)\end{array}$ & $\begin{array}{c}P \\
\text { value }\end{array}$ \\
\hline Male & $7(64 \%)$ & $4(57 \%)$ & $>.9$ \\
\hline Birth weight $(\mathrm{kg})$ & $3(2.6-3.5)$ & $3.7(3.2-4.2)$ & .003 \\
\hline Gestational age (wk) & $39(37-41)$ & $40(39-41)$ & .025 \\
\hline Head circumference $(\mathrm{cm})$ & $35(33-36)$ & $35(32-37)$ & .28 \\
\hline Prenatal diagnosis & $5(45 \%)$ & $3(43 \%)$ & $>.9$ \\
\hline Apgar score at $5 \mathrm{~min}$ & $9(8-10)$ & $9(9-10)$ & .51 \\
\hline Balloon atrial septostomy & $8(73 \%)$ & $7(100 \%)$ & .25 \\
\hline Lowest $\mathrm{pH}$ & $7.32(6.89-7.38)$ & $7.14(7.07-7.39)$ & .17 \\
\hline $\begin{array}{l}\text { Lowest mean arterial pressure } \\
\qquad(\mathrm{mm} \mathrm{Hg})\end{array}$ & $39(34-48)$ & $39(33-44)$ & .75 \\
\hline Ventricular septal defect & $0(0 \%)$ & $3(43 \%)$ & .04 \\
\hline $\begin{array}{l}\text { Cardiopulmonary bypass time } \\
\text { (min) }\end{array}$ & $174(144-221)$ & $171(150-326)$ & .47 \\
\hline Aortic crossclamp time (min) & $92(74-107)$ & $84(71-179)$ & .26 \\
\hline $\begin{array}{l}\text { Minimum temperature } \\
\text { on bypass }\left({ }^{\circ} \mathrm{C}\right)\end{array}$ & $22(19-22)$ & $22(21-25)$ & .28 \\
\hline
\end{tabular}

Data are median with range, or number and percentage of patients for categoric data. $D H C A$, Deep hypothermic circulatory arrest.

respectively. No clinical seizures were observed in either group. Three infants (2 in DHCA group, 1 in non-DHCA group) had electrographic seizures during $\mathrm{CPB}$. One infant in the non-DHCA group had a single 3-minute electrographic seizure during the postoperative intensive care phase. The $\mathrm{aEEG}_{\min }$ was significantly higher after bypass than the pre-bypass values in both groups $(P<.05)$; however, it was significantly lower in the DHCA group than in the non-DHCA group from the time of removal of the aortic crossclamp, during weaning from $\mathrm{CPB}$, and immediately after CPB $(P<.005)$. There was no significant difference between groups during and immediately after CPB in TOI $(P=.128)$, FTOE $(P=.068)$, and core temperature $(P=.06)$. The DHCA nadir was not significantly different from baseline for TOI, $\Delta \mathrm{Hb}$, and FTOE. Normalized total hemoglobin index was significantly lower than baseline at the nadir $(P<.005)$ but not at other times. The postbypass $\triangle \mathrm{Hb}, \mathrm{FTOE}$, and MAP were significantly higher than the prebypass values in the non-DHCA group $(P<.05)$ but not the DHCA group.

After transfer to intensive care, DHCA was associated with higher TOI $(P<.05)$ and lower FTOE $(P<.005)$ and core temperature $(P<.05)$ than non-DHCA CPB. In contrast, $\mathrm{aEEG}_{\mathrm{min}}, \mathrm{SaO}_{2}$, MAP, and heart rate were not significantly different between groups. There was a significant positive association between core temperature and FTOE after controlling for group ( $\beta$ coefficient $0.557 ; P<.05$ ). There was a significant increase in $\Delta \mathrm{Hb}$ with time $(P<.0001)$ and a fall in normalized total hemoglobin index in the non-DHCA group $(P<.05)$ but not in the DHCA group ( $P$ not significant). TOI increased and FTOE fell significantly with time in both groups $(P<.001)$. The $\mathrm{aEEG}_{\mathrm{min}}$ increased significantly with time in the DHCA group 


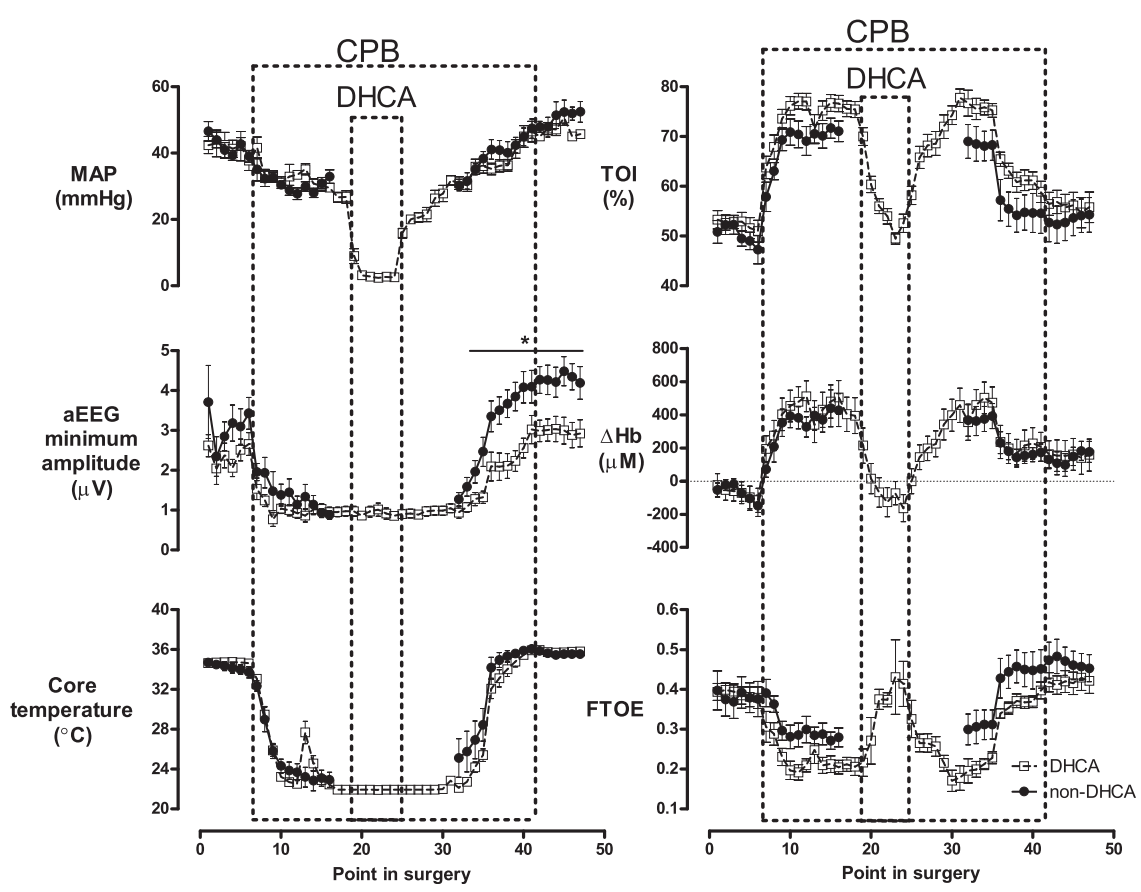

FIGURE 1. Intraoperative data for patients with and without deep hypothermic circulatory arrest $(D H C A)$ are mean \pm SEM. Time points are 5-minute averages beginning 30 minutes before and lasting until 30 minutes after cardiopulmonary bypass $(C P B)$ initiation, from 10 minutes before and lasting until 10 minutes after aortic crossclamping, from 10 minutes before deep hypothermic circulatory arrest, minute averages of deep hypothermic circulatory arrest, deep hypothermic circulatory arrest nadir, deep hypothermic circulatory arrest off, minute averages for 5 minutes after deep hypothermic circulatory arrest, 5-minute average of 6 to 10 minutes after deep hypothermic circulatory arrest, from 10 minutes before and lasting until 10 minutes after aortic unclamping, and from 30 minutes before and lasting until 30 minutes after bypass off. Asterisk indicates $P<.05$ by post hoc contrasts. MAP, Mean arterial blood pressure; TOI, tissue oxygenation index, $a E E G$, amplitude-integrated electroencephalography; $\triangle H b$, difference in hemoglobin; FTOE, fractional tissue oxygen extraction.

$(P<.0001)$. MAP fell significantly from 4 hours $(P<.0005$ in both groups; post hoc, significant from 5 hours in both groups) but remained steady thereafter.

Preoperative WMI was present in 3 infants in the DHCA group $(27.3 \%)$ and 2 in the non-DHCA group (28.6\%; $P$ not significant). New postoperative WMI was present in $2(18.2 \%)$ and $3(42.9 \%)$ infants, respectively $(P$ not significant); none of these patients had WMI before surgery. No cases of stroke were seen.

\section{DISCUSSION}

This prospective, observational study suggests that DHCA for a median of 5 minutes during cardiac surgery was associated with consistent neurophysiologic changes relative to CPB without DHCA. First, $\mathrm{aEEG}_{\min }$ took longer to recover and was suppressed to a greater extent during rewarming and immediately after $\mathrm{CPB}$. Second, during recovery from surgery in intensive care, FTOE was lower in the DHCA group with greater intracerebral oxygenation, despite similar peripheral oxygen saturation and arterial blood pressure. These findings were associated with no apparent increase in electrographic seizures or increase in risk of new brain injury on MRI. The most likely explanation for these results is that short periods of DHCA during the ASO are associated with a transient suppression in brain metabolism with associated reduction in oxygen extraction and suppression of electrical activity.

These findings should be interpreted cautiously. The sample size is small, the groups were not randomized, and infants in the DHCA group were significantly smaller, were less mature, and were entirely free of VSDs, although crossclamp and CPB times were similar between groups. We therefore cannot exclude the possibility that differences between groups may have contributed to functional changes after surgery. Further, we did not have any markers of systemic blood flow, such as cardiac output or systemic venous oxygen saturation, which might have helped us to interpret the changes in cerebral oxygenation. These results should therefore be confirmed in a larger cohort with random assignment of DHCA.

The aEEG and NIRS changes during surgery in this study are consistent with previous reports, ${ }^{14,15}$ with profound depression of EEG activity, a dramatic increase in intracerebral oxygenation during bypass, and a relative fall in intracerebral oxygenation during DHCA. Previous studies in piglets ${ }^{14}$ and human infants ${ }^{15}$ have reported that cerebral oxygenation falls well below baseline during longer-duration DHCA than that used in this present study. Similar to our findings, however, these investigators observed a fall in intracerebral oxygenation to near baseline values 

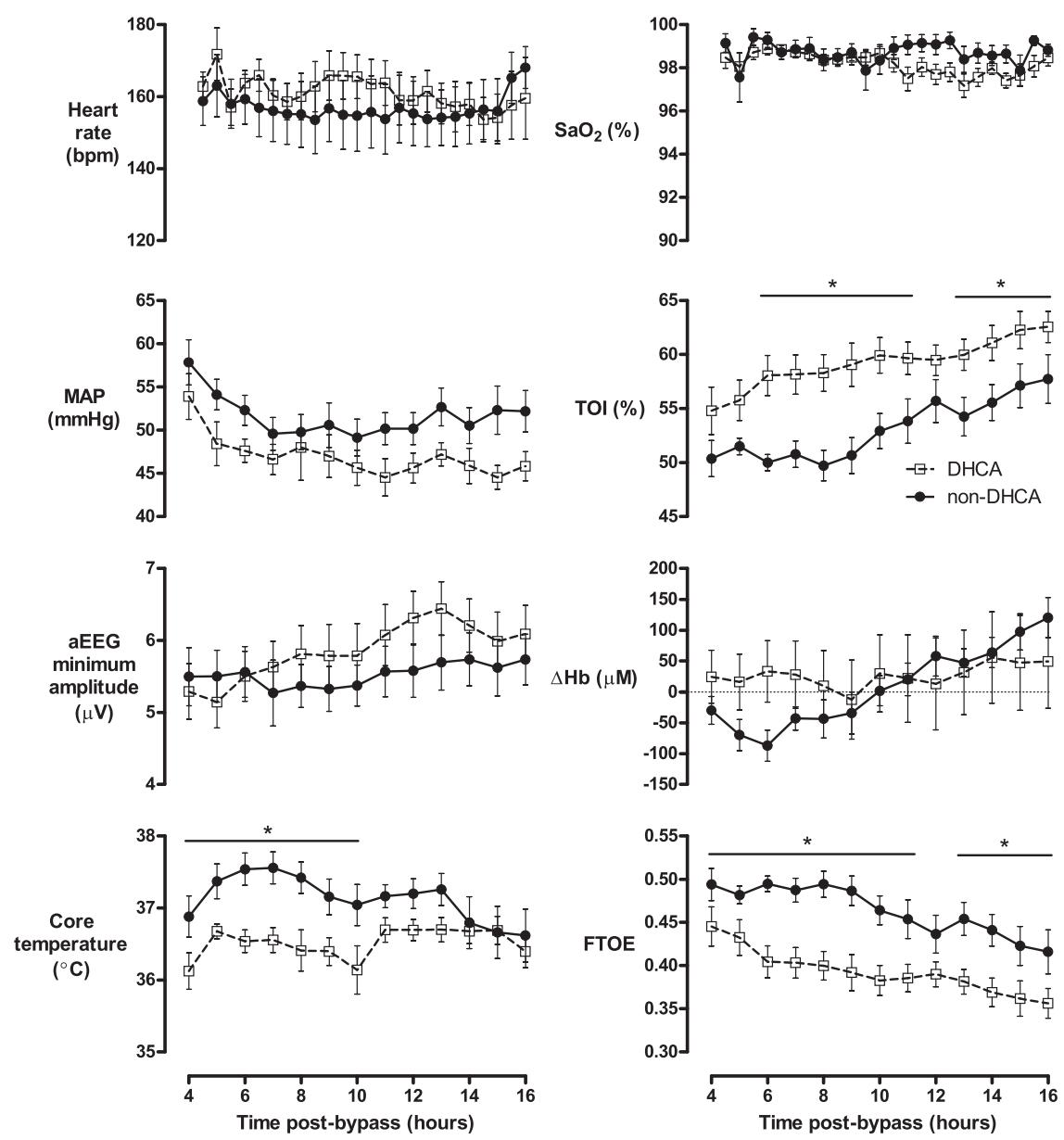

FIGURE 2. Postoperative data for patients with and without deep hypothermic circulatory arrest $(D H C A)$ are hourly mean \pm SEM. Time 0 represents the end of bypass. Asterisk indicates $P<.05$ by post hoc contrasts. $\mathrm{Sao}_{2}$, Arterial oxygen saturation; MAP, mean arterial blood pressure; TOI, tissue oxygenation index, $a E E G$, amplitude-integrated electroencephalography; $\triangle H b$, difference in hemoglobin; FTOE, fractional tissue oxygen extraction.

after 5 minutes of arrest, which was the median duration of arrest in our study. It is likely that this greater deoxygenation in the DHCA group relative to the non-DHCA group in our study contributed to the reduced recovery of the $\mathrm{aEEG}_{\text {min }}$ during rewarming and immediately after CPB. Consistent with this conjecture, there is evidence of rapid depletion of cellular nicotinamide adenine dinucleotide after DHCA in the piglet, demonstrating that DHCA is sufficient to induce acute primary failure of oxidative metabolism. ${ }^{16}$

After surgery, reduced cerebral oxygen extraction with increased cerebral oxygenation in the first 16 hours strongly suggests that DHCA was associated with depressed cerebral oxidative metabolism relative to CPB. Cerebral hypoxiaischemia is consistently associated with reduced oxidative metabolism during the recovery phase in both preclini$\mathrm{cal}^{17,18}$ and clinical ${ }^{19}$ settings. Furthermore, secondary hypoperfusion after 10 minutes of hypoxia-ischemia in near-term fetal sheep was associated with increased transcutaneously measured cortical $\mathrm{Po}_{2},{ }^{17}$ strongly implying that hypoperfusion reflects actively mediated suppression of cerebral metabolism. The mechanisms of this hypometabolism after hypoxia-ischemia are only partly understood, but there is evidence that it is mediated at least in part by neuroinhibitory factors such as allopregnanalone ${ }^{20}$ and norepinephrine,${ }^{21}$ and that blocking these mechanisms exacerbates neural injury.

The greater TOI after DHCA in this study was not mediated by changes in oxygen content, because after surgery $\mathrm{SaO}_{2}$ was consistently greater than $95 \%$ in both groups and hematocrit was stable. Potentially, an increase in systemic cardiac output could improve cerebral oxygen delivery and thus increase TOI with reduced oxygen extraction. DHCA was not, however, associated with a significant effect on arterial blood pressure or $\Delta \mathrm{Hb}$, an index of cerebral blood flow. ${ }^{13}$ Consistent with this finding, Doppler ultrasonographic studies strongly suggest that cerebral blood flow does not increase after DHCA. ${ }^{22}$

TOI increased significantly with time in both groups in the postoperative period, and $\Delta \mathrm{Hb}$ increased significantly in the non-DHCA group. Secondary hypoperfusion 
typically resolves from 6 to 8 hours after hypoxia-ischemia, and thus resolution of this phase in the latter half of the recording period could potentially have contributed to the increase in TOI. In addition, cardiac output typically falls for 8 to 12 hours after the ASO and then recovers during the next 12 hours. ${ }^{23}$ This pattern could well have contributed to the increase in TOI and thus $\Delta \mathrm{Hb}$ in both groups that was seen after 8 to 12 hours.

Core temperature was lower in the DHCA group than in the non-DHCA group from 4 to 10 hours after surgery. Because hypothermia reduces brain metabolism, this potentially may have contributed to reduced oxygen extraction. Because there is only a $5 \%$ reduction in metabolism per degree $^{24}$ and there was only a $1^{\circ}$ difference between groups, this does not seem sufficient to account for the magnitude of reduced oxygen extraction in this study. It is unclear why core temperature was lower, considering that there were no differences in the temperature management protocols during rewarming both in the operating room and during intensive care. This difference may reflect the younger gestational age of the DHCA group, with consequent reduced body mass and subcutaneous fat stores leading to greater heat loss. Alternatively, because the brain is a significant source of heat, it is possible that suppression of cerebral metabolism after DHCA actually contributed to a fall in body temperature ${ }^{25}$; however, we cannot rule out other mechanisms, such as hypothalamic dysfunction.

Similarly to other recent reports, ${ }^{6-9}$ more than a quarter of the infants in this series showed new, mild WMI lesions after surgery. There was no apparent increase in risk with DHCA, however, and no patients had evidence of grey matter injury, supporting the hypothesis that the current physiologic findings represent a transient and reversible suppression in cerebral metabolism. Intriguingly, we found significantly reduced FTOE in the DHCA group within 4 hours after surgery in contrast to previous reports in infants with severe hypoxic-ischemic encephalopathy, who showed a proportionately larger fall in FTOE but only from 24 hours after the insult. ${ }^{19}$ We and others have previously reported preexisting WMI in $20 \%$ to $30 \%$ of infants before surgery, ${ }^{6-9}$ consistent with the findings in this study. Potentially then, the earlier decline may reflect previous neural compromise. ${ }^{8}$

In summary, this observational study suggests that brief circulatory arrest during the ASO may be associated with suppressed cerebral oxygen extraction in the early postoperative period, consistent with reduced mitochondrial oxidative metabolism. There was no evidence of greater risk of WMI after DHCA, suggesting that these changes may represent a potentially protective suppression of metabolism during recovery. These findings should be confirmed in a randomized clinical trial, and long-term neurodevelopmental follow-up is needed to confirm whether DHCA is associated with functional effects in later childhood.
We acknowledge the biomedical statistics service at the University of Auckland for their statistical analysis; we acknowledge the cardiac surgeons, cardiologists, anesthetists, perfusionists, and pediatric intensive care unit staff at Starship Children's Hospital for their assistance with this study; and we acknowledge Dr Ayton Hope for MRI interpretation and Dr Julia Gunn for advice on seizure analysis.

\section{References}

1. Jonas RA. Deep hypothermic circulatory arrest: current status and indications. Semin Thorac Cardiovasc Surg Pediatr Card Surg Annu. 2002;5:76-88.

2. Newburger JW, Jonas RA, Wernovsky G, Wypij D, Hickey PR, Kuban KC, et al. A comparison of the perioperative neurologic effects of hypothermic circulatory arrest versus low-flow cardiopulmonary bypass in infant heart surgery. $\mathrm{N} \mathrm{Engl}$ J Med. 1993;329:1057-64.

3. Bellinger DC, Wypij D, Kuban KC, Rappaport LA, Hickey PR, Wernovsky G, et al. Developmental and neurological status of children at 4 years of age after heart surgery with hypothermic circulatory arrest or low-flow cardiopulmonary bypass. Circulation. 1999;100:526-32.

4. Hövels-Gürich HH, Seghaye MC, Schnitker R, Wiesner M, Huber W, Minkenberg R, et al. Long-term neurodevelopmental outcomes in school-aged children after neonatal arterial switch operation. J Thorac Cardiovasc Surg. 2002;124:448-58.

5. Bellinger DC, Newburger JW, Wypij D, Kuban KC, duPlesssis AJ, Rappaport LA. Behaviour at eight years in children with surgically corrected transposition: The Boston Circulatory Arrest Trial. Cardiol Young. 2009;19:86-97.

6. Beca J, Gunn J, Coleman L, Hope A, Whelan LC, Gentles T, et al. Pre-operative brain injury in newborn infants with transposition of the great arteries occurs at rates similar to other complex congenital heart disease and is not related to balloon atrial septostomy. J Am Coll Cardiol. 2009;53:1807-11.

7. McQuillen PS, Barkovich AJ, Hamrick SE, Perez M, Ward P, Glidden DV, et al. Temporal and anatomic risk profile of brain injury with neonatal repair of congenital heart defects. Stroke. 2007;38(2 Suppl):736-41.

8. Andropoulos DB, Hunter JV, Nelson DP, Stayer SA, Stark AR, McKenzie ED, et al. Brain immaturity is associated with brain injury before and after neonatal cardiac surgery with high-flow bypass and cerebral oxygenation monitoring. J Thorac Cardiovasc Surg. 2010;139:543-56.

9. Petit CJ, Rome JJ, Wernovsky G, Mason SE, Shera DM, Nicolson SC, et al. Preoperative brain injury in transposition of the great arteries is associated with oxygenation and time to surgery, not balloon atrial septostomy. Circulation. 2009;119:709-16.

10. Galli KK, Zimmerman RA, Jarvik GP, Wernovsky G, Kuypers MK, Clancy RR, et al. Periventricular leukomalacia is common after neonatal cardiac surgery. J Thorac Cardiovasc Surg. 2004;127:692-704.

11. Kussman BD, Wypij D, Laussen PC, Soul JS, Bellinger DC, DiNardo JA, et al. Relationship of intraoperative cerebral oxygen saturation to neurodevelopmental outcome and brain magnetic resonance imaging at 1 year of age in infants undergoing biventricular repair. Circulation. 2010;122:245-54.

12. Gunn JK, Beca J, Penny DJ, Horton SB, d'Udekem YA, Brizard CP, et al. Amplitude-integrated electroencephalography and brain injury in infants undergoing Norwood-type operations. Ann Thorac Surg. 2012;93:170-6.

13. Bassan H, Gauvreau K, Newburger JW, Tsuji M, Limperopoulos C, Soul JS, et al. Identification of pressure passive cerebral perfusion and its mediators after infant cardiac surgery. Pediatr Res. 2005;57:35-41.

14. Shin'oka T, Nollert G, Shum-Tim D, du Plessis A, Jonas RA. Utility of nearinfrared spectroscopic measurements during deep hypothermic circulatory arrest. Ann Thorac Surg. 2000;69:578-83.

15. du Plessis AJ, Newburger J, Jonas RA, Hickey P, Naruse H, Tsuji M, et al. Cerebral oxygen supply and utilization during infant cardiac surgery. Ann Neurol. 1995;37:488-97.

16. Chock VY, Amir G, Davis CR, Ramamoorthy C, Riemer RK, Ray D, et al. Antegrade cerebral perfusion reduces apoptotic neuronal injury in a neonatal piglet model of cardiopulmonary bypass. J Thorac Cardiovasc Surg. 2006;131:659-65.

17. Jensen EC, Bennet L, Hunter CJ, Power GG, Gunn AJ. Post-hypoxic hypoperfusion is associated with suppression of cerebral metabolism and increased tissue oxygenation in near-term fetal sheep. $J$ Physiol. 2006;572:131-9.

18. Kurth CD, McCann JC, Wu J, Miles L, Loepke AW. Cerebral oxygen saturationtime threshold for hypoxic-ischemic injury in piglets. Anesth Analg. 2009;108: 1268-77.

19. Toet MC, Lemmers PM, van Schelven LJ, van Bel F. Cerebral oxygenation and electrical activity after birth asphyxia: their relation to outcome. Pediatrics. 2006;117:333-9. 
20. Yawno T, Yan EB, Walker DW, Hirst JJ. Inhibition of neurosteroid synthesis increases asphyxia-induced brain injury in the late gestation fetal sheep. Neuroscience. 2007; 146:1726-33.

21. Quaedackers JS, Roelfsema V, Heineman E, Gunn AJ, Bennet L. The role of the sympathetic nervous system in post-asphyxial intestinal hypoperfusion in the preterm sheep fetus. J Physiol. 2004;557(Pt 3):1033-44.

22. O'Hare B, Bissonnette B, Bohn D, Cox P, Williams W. Persistent low cerebral blood flow velocity following profound hypothermic circulatory arrest in infants. Can J Anaesth. 1995;42:964-71.
23. Wernovsky G, Wypij D, Jonas RA, Mayer JE Jr, Hanley FL, Hickey PR, et al Postoperative course and hemodynamic profile after the arterial switch operation in neonates and infants. A comparison of low-flow cardiopulmonary bypass and circulatory arrest. Circulation. 1995;92:2226-35.

24. Laptook AR, Corbett RJ, Sterett R, Garcia D, Tollefsbol G. Quantitative relationship between brain temperature and energy utilization rate measured in vivo using ${ }^{31} \mathrm{P}$ and ${ }^{1} \mathrm{H}$ magnetic resonance spectroscopy. Pediatr Res. 1995;38:919-25.

25. Erecinska M, Thoresen M, Silver IA. Effects of hypothermia on energy metabolism in mammalian central nervous system. J Cereb Blood Flow Metab. 2003;23:513-30. 